\title{
Improving the Performance of an Electro-Hydraulic Load-Sensing Proportional Control Valve
}

\author{
Raffaele Babbone, Massimo Milani, Luca Montorsi and Fabrizio Paltrinieri \\ DISMI (Department of Sciences and Methods for Engineering), University of Modena and Reggio Emilia, Reggio Emilia 42122, Italy
}

Received: January 30, 2013 / Accepted: June 14, 2013 / Published: December 31, 2013.

\begin{abstract}
The paper deals with the simulation and the experimental verification of the hydraulic behavior of an electro-hydraulic load-sensing proportional control valve. An innovative CAE (computer aided engineering) methodology, developed combining CFD (computational fluid dynamics) simulations with lumped and distributed numerical modeling, is firstly introduced and tailored by comparing the numerical results with measurements coming from an experimental campaign performed for a wide range of pressure loads and metered flow rates. Then, both the reliability and the limits of the numerical approach are highlighted through a detailed numerical vs. experimental comparison, involving the pressure of the main hydraulic lines, the flow rate through the first section and the local compensator displacement. Finally, the CAE methodology has been applied for assessing the internal ducts hydraulic permeability and the local compensator spring pre-load influence on the control valve metering curves. At the end of this analysis, an optimized design configuration, featuring a maximum controlled volumetric flow rate increased of more than $25 \%$, has been proposed.
\end{abstract}

Key words: Proportional control valve, load-sensing, CFD, lumped and distributed parameters modeling.

\section{Nomenclature}

$\begin{array}{ll}B & \text { Bulk modulus }(\mathrm{Pa}) \\ d & \text { Diameter }(\mathrm{m}) \\ F_{0} & \text { Spring pre-load }(\mathrm{N}) \\ p & \text { Pressure }(\mathrm{Pa}) \\ Q & \text { Volumetric flow rate }\left(\mathrm{m}^{3} / \mathrm{s}\right) \\ t & \text { Time }(\mathrm{s}) \\ x & \text { Displacement }(\mathrm{m}) \\ \Delta & \text { Percentage variation }(\%) \\ \mu & \text { Fluid dynamic viscosity }(\mathrm{Pa} \cdot \mathrm{s}) \\ \rho & \text { Fluid density }\left(\mathrm{kg} / \mathrm{m}^{3}\right)\end{array}$

\section{Subscripts}

$\begin{array}{ll}I N & \text { Inlet port } \\ L C & \text { Local compensator } \\ \text { LOAD } & \text { Load } \\ \text { LS } & \text { Load sensing } \\ P 1 & \text { Local compensator downstream } \\ R 1 & \text { First slice } \\ S P & \text { Main spool }\end{array}$

Corresponding author: Fabrizio Paltrinieri, Ph.D., assistant professor, research fields: modelling and design of fluid power systems and components. E-mail: fabrizio.paltrinieri@unimore.it.

\section{Introduction}

In the recent past, the technical and the technological developments have given a strong impulse to the performance improvement of hydraulic systems applied to industrial, automotive, off-road and mobile actuations. In this direction, a particular attention has been devoted to the increase of the specific power and of the overall efficiency of hydraulic systems, following design strategies particularly addressed to the mechatronic integration and to the energetic qualification of the hydraulic components.

Among the available options, the load-sensing approach represents the most reliable solution to comply stringent design requirements, both lowering the hydraulic systems dissipations, and increasing the manageability and the usefulness of multiple actuations. As well known, the core of the load-sensing concept to system integration has been represented by the proportional, electro-hydraulically controlled and hydraulically compensated control block, in which 
different control sections allows to metering the desired hydraulic power to multiple actuations with high precision, fast answer, reliability and limited weights.

In the last two decades, the rapid growth of the available computing power has determined a strong impulse to the development of CAE (computer aided engineering) methodologies applied to the study of the existing systems and components operational modes and to the definition of optimized solutions in terms of energy saving and performance improvement. Among them, the combined use of CFD (computational fluid dynamics) simulations and lumped and distributed numerical modeling can be a very useful tool for supporting the design process of the complex hydraulic components generally adopted for load sensing applications.

In literature, many interesting contributions in this field have been proposed by several authors. For instance, the metering edge geometry effects are accurately investigated in Refs. [1, 2], while the hydraulic servo-systems stationary and dynamic efflux characteristics are presented in Ref. [3]. Two remarkable experimental studies, aimed at understanding the influence of the flow forces acting on hydraulic valves moving elements, are proposed in Refs. [4, 5].

Moreover, several examples of CFD simulations involved for the estimation of the flow forces and the discharge coefficients charactering hydraulic components for industrial applications can be found in Refs. [6-9]. On the other hand, in Refs. [10, 11] the adoption of lumped and distributed numerical modeling for simulating the operation of volumetric pumps for IC engine lubrication is presented and validated.

This paper deals with the definition of some design strategies needed to improve the performance of a pre-compensated electro-hydraulic load-sensing proportional control valve, by means of a CAE methodology based on the 3D CFD multidimensional analysis, properly combined with the dynamic unsteady characterization coming from a lumped and distributed parameter modeling. After the comprehensive description of the methodology adopted for the analysis of the hydraulic distributor metering characteristics, the paper carefully details the steps followed to tailor the lumped and distributed numerical model, both through the multidimensional CFD analysis applied to transient multidimensional internal flows, and through the numerical vs. experimental hydraulic characteristics comparison.

More in details, a 3D CFD multidimensional analysis is addressed to the definition of steady and transient efflux features, like the discharge coefficient and the efflux angle, and the control valve operating characteristics are determined involving both Newtonian and non-Newtonian fluids. Moreover, the results detailing the load-sensing proportional control valve dynamics are validated through an exhaustive numerical vs. experimental comparison, for a wide range of metered flow rates and pressure levels.

The second part of the paper is devoted to the application of the CAE multidimensional methodology to the control valve performance improvement, with particular care addressed to the recognition of the best design strategies needed to increase the control valve permeability and controllability.

\section{Electro-Hydraulic Load-Sensing Proportional Control Valve}

The load-sensing concept is widely employed for hydraulic systems when a stable and comfortable control of the actuators, particularly subjected to high frequency load variations, is required. This technology is nowadays extensively applied in order to assure higher efficiency values of the hydraulic circuits for industrial, agricultural and earth moving applications.

In this paper, the operational mode of an electro-hydraulic load-sensing proportional control valve, commonly produced by hydraulic components manufacturers, has been studied with the aim to 
improve the efflux performance in terms of pressure drops reduction and maximum delivered flow rate.

In Fig. 1, the control valve general structure is presented and the following main parts assembled together can be identified:

- An inlet cover equipped with a main compensator, that regulates the pressure drop between the control block inlet port and the maximum pressure load, a directly actuated pressure relief valve, limiting the load sensing line pressure, an electrical venting valve and a bleeding valve for the load sensing piloting signal;

- Two or more pre-compensated sections, each one provided with a check and a shuttle valve directly connected to the load sensing piloting line;

- An outlet cover for closing the block.

The proportional control valve, shown in Fig. 1, can deliver an almost stable volumetric flow rate even if the loads applied to the actuators are rapidly changing. In fact, a local compensator is mounted upstream with respect to the main spool of each section with the feature of maintaining a constant pressure drop across the metering edges.

\section{Combined CAE Methodology}

In this paragraph, a CAE methodology based on the 3D CFD multidimensional analysis, properly combined with the dynamic unsteady characterization coming from a lumped and distributed parameter modeling, is presented and applied for the definition of

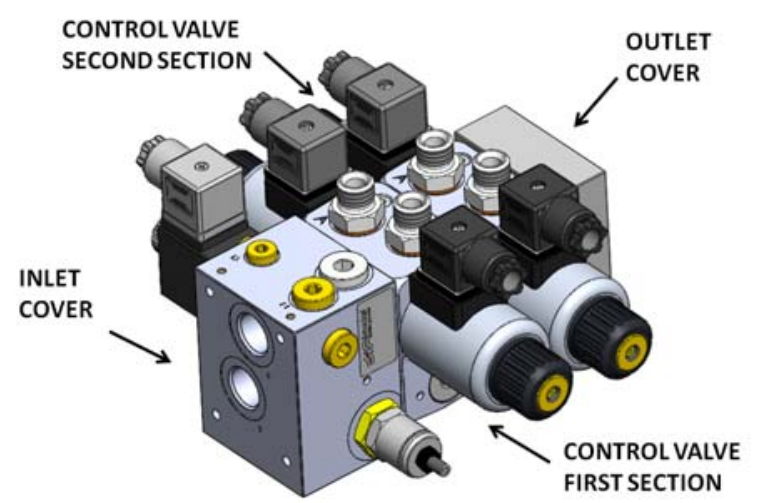

Fig. 1 Electro-hydraulic load-sensing proportional control valve. some design strategies needed to improve the performance of a pre-compensated electro-hydraulic load-sensing proportional control valve.

\subsection{Lumped Parameters Approach}

First of all, the capabilities of the LMS Imagine.Lab AMESim, Rev. 9.1, simulating environment [12] have been employed in order to develop a particularly detailed model of the proportional control valve, starting from the elementary components of the "Hydraulic", "Mechanical", "Signal, Control and Observers" and "Hydraulic Component Design" AMESim libraries. The following elements, and corresponding sub-models, have been selected:

- Hydraulic volume with pressure dynamics, BHC11: represents the control valve internal volumes and permits the computation of the pressure variation due to spool displacement and internal flows;

- Spool with annular section orifice, BAO011, and spool with hole section orifice, BAO042: introduced for modeling the metering edges of the inlet cover compensator, the local compensator and the bleeding valve spools;

- The piston, BAP11, and the piston with spring, BAP015: in order to account for the spool piloting surfaces and the spring elastic characteristics;

- Leakage and viscous friction, BAF11: for the calculation of the control valve internal leakages and the friction forces acting on the spools;

- Ball poppet with sharp edge seat, BAP21, and poppet with sharp edge seat, BAP025: adopted for the estimation of both the one-dimensional motion and the metered flow rate respectively through the spherical check and shuttle valves and the conical poppet relief valve with sharp edges seat;

- The variable hydraulic orifice, VOR02: generates the variable load pressure applied to the control valve;

- The fixed hydraulic orifice, OR000: adopted for the estimation of the control valve internal pressure drop due to the presence of hydraulic contractions, expansions, bends and calibrated holes drilled inside 
the inlet cover and the local compensator;

- The hydraulic tank, TK000: in order to model constant pressure sources like the low pressure and the drain ambient;

- The indexed hydraulic fluid properties, FP04: introduced to consider the actual working fluid;

- The mass with friction and ideal end stops, MAS005: in order to account for the inertial characteristics of all the control valve moving elements;

- The signal source giving time, CLOC: generates the simulation time inside the model;

- The signal function of output defined by ASCII, FXA01: inputs data from ASCII files representing both the displacement of the main spool and the control valve inlet flow rate measured during the experimental tests.

Moreover, a customized library, properly tailored for the estimation of the flow rates through the metering edges of non common shape notched spools, has been involved for predicting the hydraulic permeability of the proportional control valve. With reference to Fig. 2, in which an overall sketch picture of the AMESim lumped parameter numerical model is proposed, the previously mentioned customized components are depicted in black color.

\subsection{D CFD Multidimensional Analysis}

The accuracy of the lumped and distributed parameter numerical model has been improved by means of further 3D CFD multidimensional simulations carried out by applying the open source computational fluid dynamics code OpenFOAM. In particular, the local compensator metering conditions have been investigated by assuming an incompressible efflux of both Newtonian and non-Newtonian fluids. More details about the modeling features and the numerical results can be found in Ref. [13] while the CFD computational grid and a zoomed view of metering zone mesh refinement are shown in Fig. 3.

Moreover, the results gained from the CFD analysis, mainly in terms of discharge coefficients and flow acceleration angles, have been employed for calibrating the AMESim numerical model and, thus, the reliability of the overall CAE methodology has been enhanced.

\section{Results and Discussion}

In this paragraph, the reliability of the lumped and distributed numerical model has been tested throughout

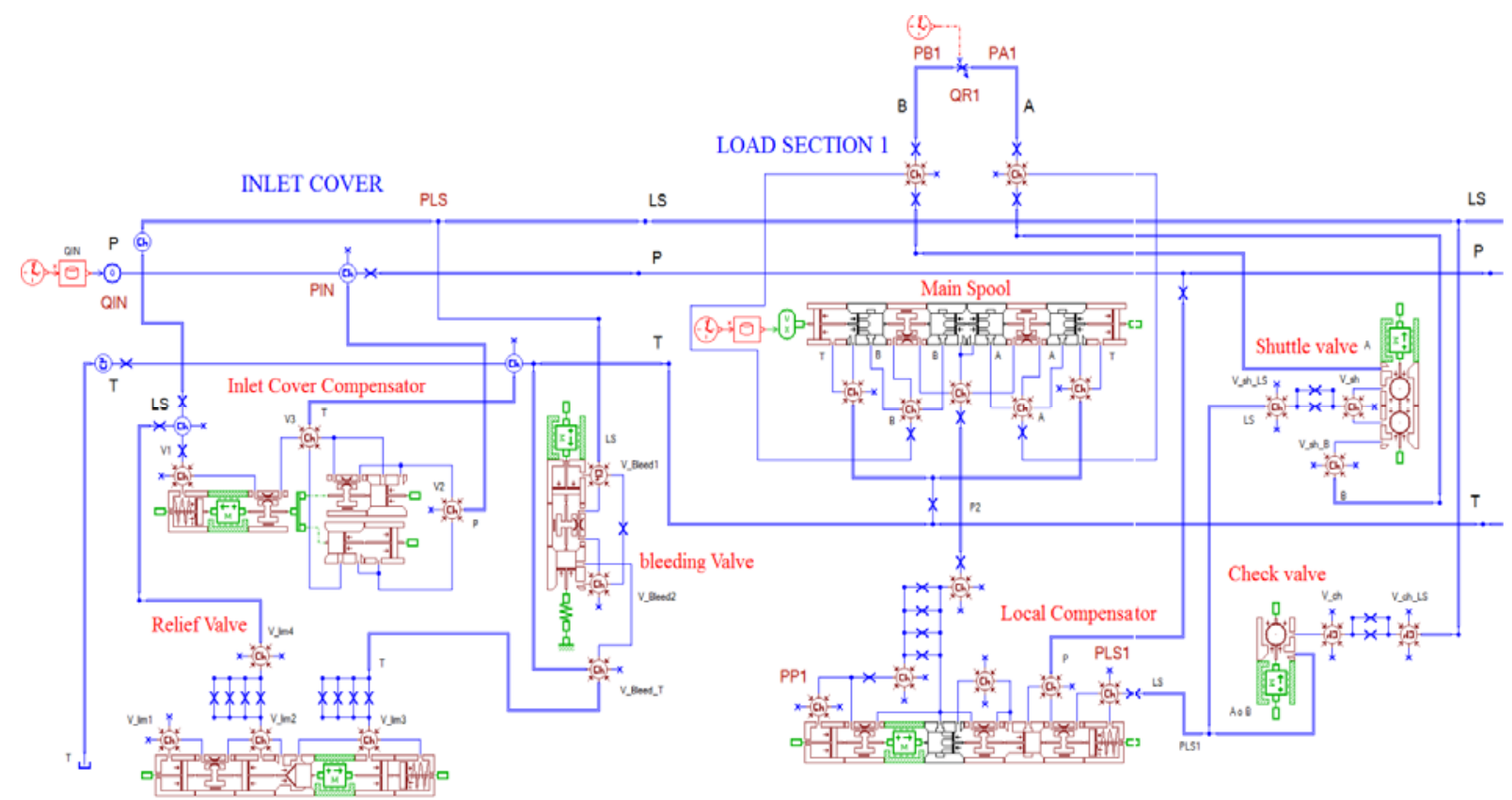

Fig. 2 Sketch picture of the AMESim lumped parameter numerical model. 

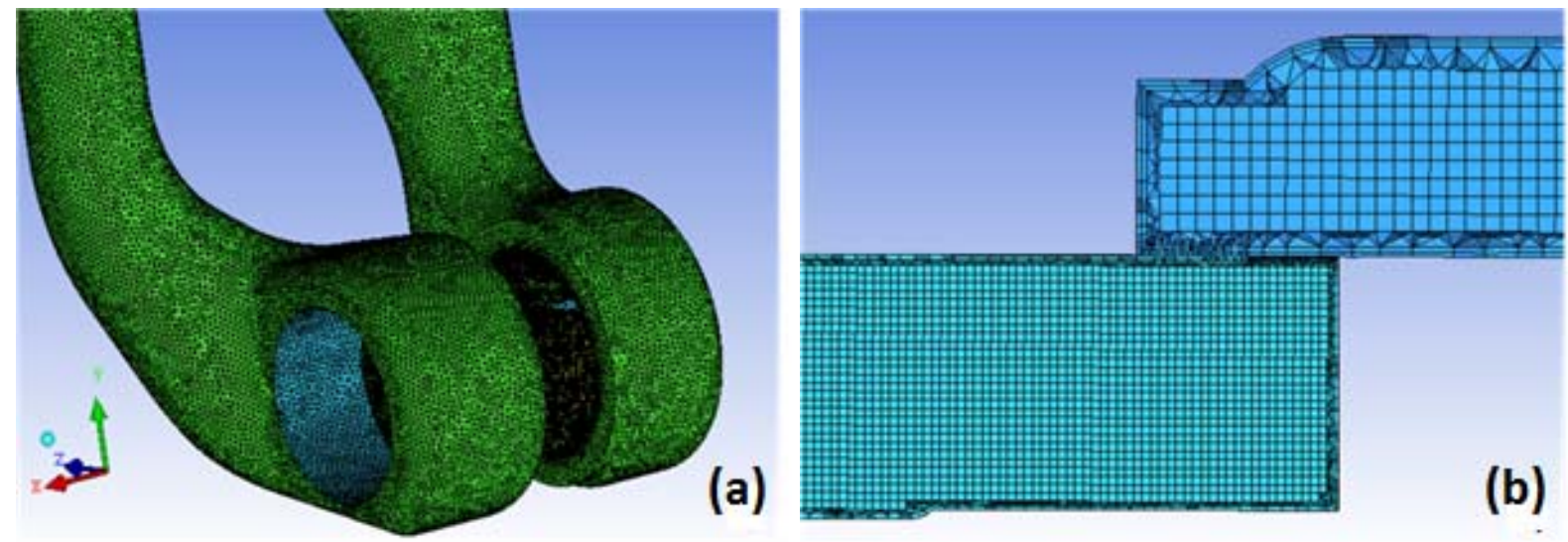

Fig. 3 (a) CFD computational grid and (b) zoomed view of the metering section.

a detailed numerical vs. experimental comparison, performed for pressure loads applied to the control valve spanning in the range from 100 bar to 200 bar. After that, the capabilities of the validated model have been applied with the aim to identify an optimized geometrical configuration, characterized by an increased maximum controlled volumetric flow rate. More in details, the analysis have been focused on the influence of the internal ducts hydraulic conductance and of the local compensator spring pre-load.

\subsection{Numerical Model Validation}

An exhaustive experimental campaign has been performed in order to enhance the predictive capability of the AMESim numerical model. In Fig. 4, the test rig involved for the experiments is showed: in particular, three KRACHT VC5 P1 PS gear type flow meters and seven HYDAC HAD-3845-B400 electronic pressure transmitters have been mounted, respectively, for volumetric flow rate and relative pressure measurements. Moreover, the main spool and the local compensator displacements have been acquired by means of two LISK LVDT linear position transducers.

The flow rate and pressure sensors positioning are illustrated in Fig. 5, where the experimental test rig hydraulic circuit is also presented. More in details, the volumetric flow rate at pump delivery and though the two slices of the control valve have been measured. The pressure sensors have been respectively set: at the distributor inlet, PIN; on the load sensing line, PLS; on

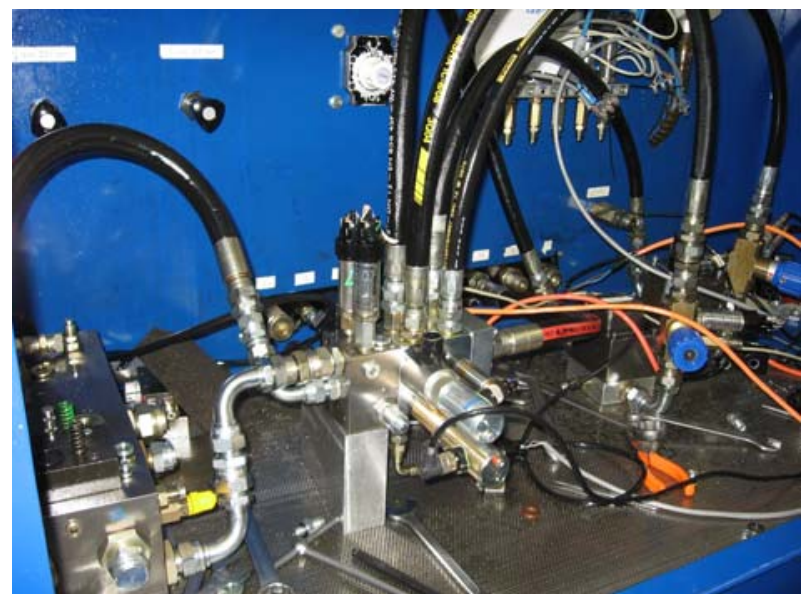

Fig. 4 Experimental setup configuration.

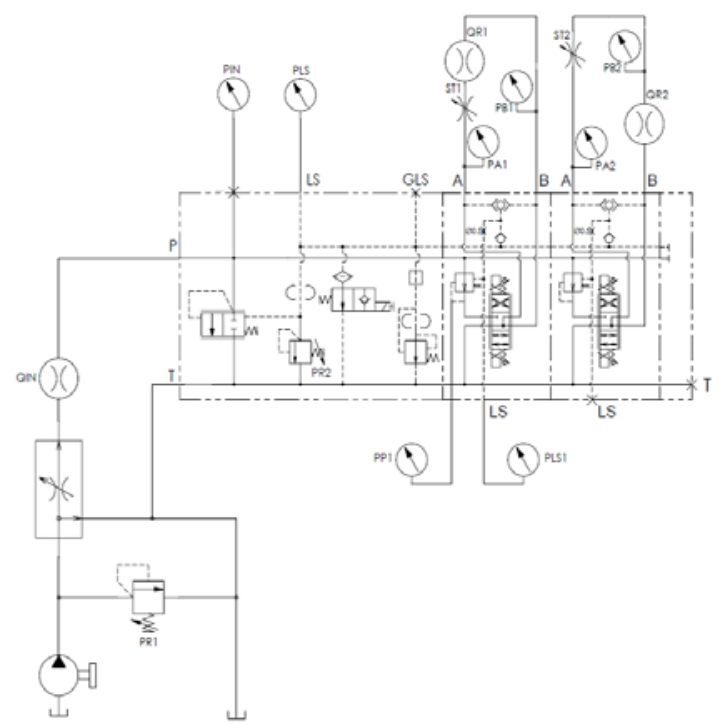

Fig. 5 Experimental test rig hydraulic circuit layout.

the contrasting active areas of the first slice local compensator, PP1 and PLS1; before and after the two variable hydraulic restrictors, ST1 and ST2, introduced 
in order to generate the back pressures acting at the two control valve outlet ports, PA1, PB1, PA2 and PB2.

During all the experimental tests, performed for three PA1 pressure levels respectively equal to about 100, 150 and 200 bar, a constant temperature of $40{ }^{\circ} \mathrm{C}$ has been maintained and a usual mineral oil, whose main physical properties are summarized in Table 1, has been used.

In Figs. 6 and 7, the measurements obtained for the volumetric flow rate at the control valve inlet port, $Q_{I N}$, and the first slice main spool displacement, $x_{S P}$, are proposed as a function of the experimental time acquisition. Analyzing Fig. 6, a constant flow rate of about $46 \mathrm{~L} / \mathrm{min}$ can be appreciated, while, as shown in Fig. 7, the first section spool is initially in a centered position $\left(x_{S P}=0 \mathrm{~mm}\right)$ and has been successively moved to its endstop $\left(x_{S P}=2.3 \mathrm{~mm}\right)$, where $\mathrm{P}$-A connection is fully opened.

In the following, the AMESim model of the whole control valve has been employed for simulating the same operating conditions applied during the experimental testing campaign. In this case, the pressure of the main hydraulic lines, the flow rate through the first slice and the local compensator displacement have been calculated once the experimental inlet flow rate, $Q_{I N}$, and the main spool displacement, $x_{S P}$, has been assumed as input parameters for the simulations.

The main results achieved for the numerical versus experimental comparison, when the lower pressure load is applied $\left(p_{L O A D}=100\right.$ bar $)$, are presented in Figs. 8-12. As far as the pressure trends as a function of the main spool displacement are concerned (Figs. 8-10), the reliability of the model is clearly evident, because the numerical and the experimental curves are almost coincident. In this case, a better result has been obtained for the control valve inlet pressure, $p_{I N}$, shown in Fig. 8, while larger differences can be noticed for the load sensing and the local compensator downstream pressures (Figs. 9 and 10), $p_{L S}$ and $p_{P 1}$, when the main spool reaches its endstop position, being however the
Table 1 Physical properties of the mineral oil used for the experimental measurements (fluid temperature $=40{ }^{\circ} \mathrm{C}$ ).

\begin{tabular}{llll}
\hline Fluid property & Symbol & Value & Unit \\
\hline Density & $\rho$ & 855.4 & $\mathrm{~kg} / \mathrm{m}^{3}$ \\
Dynamic viscosity & $\mu$ & 0.03935 & $\mathrm{~Pa} \cdot \mathrm{s}$ \\
Bulk modulus & $B$ & $1,443.7$ & $\mathrm{MPa}$ \\
\hline
\end{tabular}

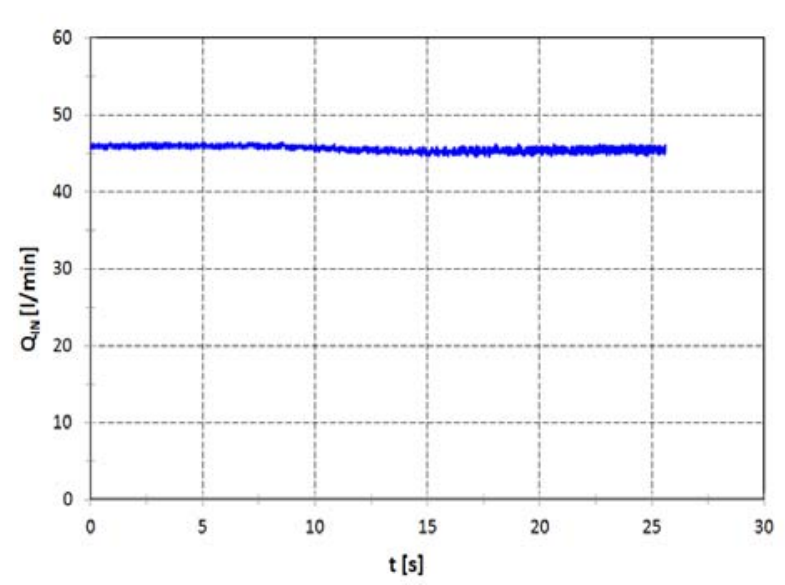

Fig. 6 Experimental flow rate at control valve inlet port.

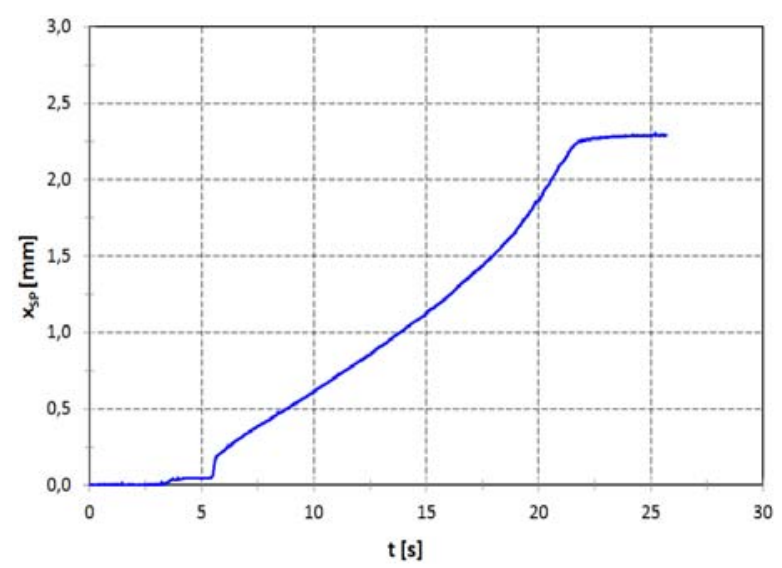

Fig. 7 Experimental first slice main spool displacement.

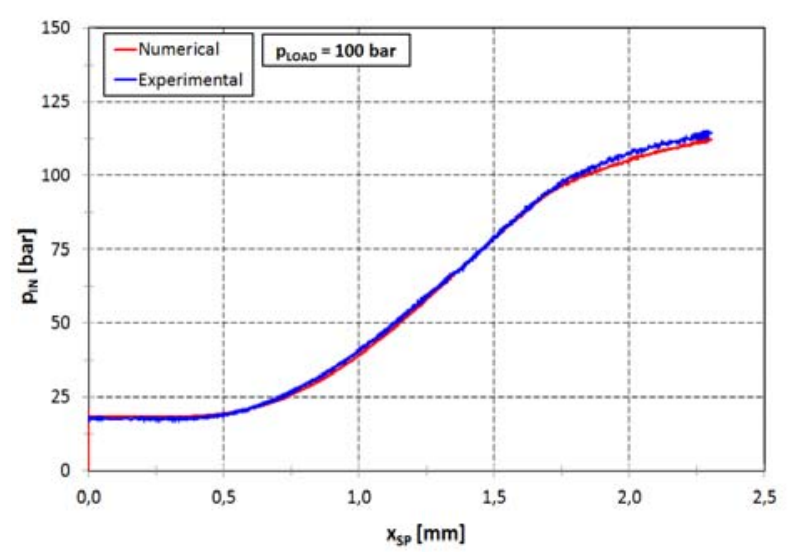

Fig. 8 Inlet pressure numerical vs. experimental comparison ( $p_{L O A D}=100$ bar $)$. 


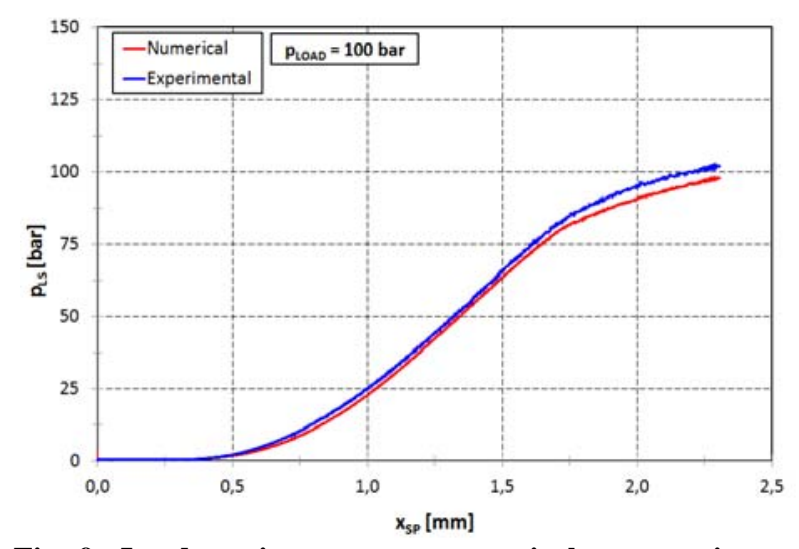

Fig. 9 Load sensing pressure numerical vs. experimental comparison $\left(p_{L O A D}=100\right.$ bar $)$.

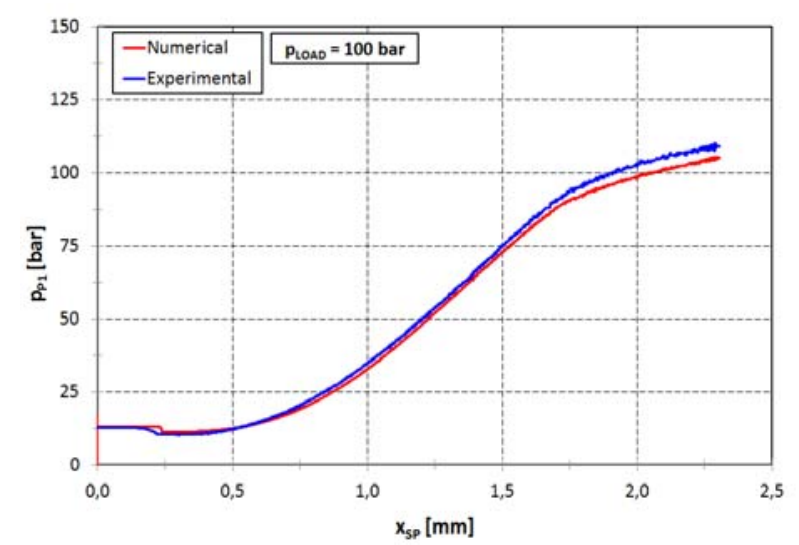

Fig. 10 Local compensator downstream pressure numerical vs. experimental comparison $\left(p_{L O A D}=100\right.$ bar $)$.

maximum percentage error always lower than $3 \%$. Furthermore, the pressure numerical tendencies are always underestimating the experimental ones.

The same considerations can be drawn also for the volumetric flow rate through the first slice of the control valve, $Q_{R 1}$, illustrated in Fig. 11.

In this case, for lower values of the main spool displacement, the combined action of the internal leakages and the inertia of the gear type flow meter have been identified as the major reasons of the numerical model overestimation. Otherwise, when the control valve is near to the maximum opening position $\left(x_{S P} \cong 1.7 \div 2.3 \mathrm{~mm}\right.$ ), an opposite trend can be observed and, as previously mentioned, the percentage difference remains always lower than $3 \%$.

A minor precision has been obtained for the local compensator displacement, $x_{L C}$, shown in Fig. 12. For

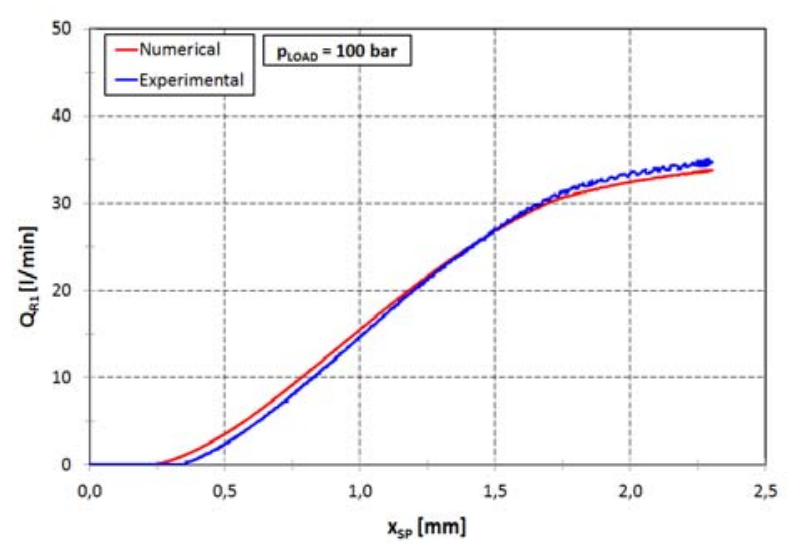

Fig. 11 First slice volumetric flow rate numerical vs. experimental comparison $\left(p_{L O A D}=100 \mathrm{bar}\right)$.

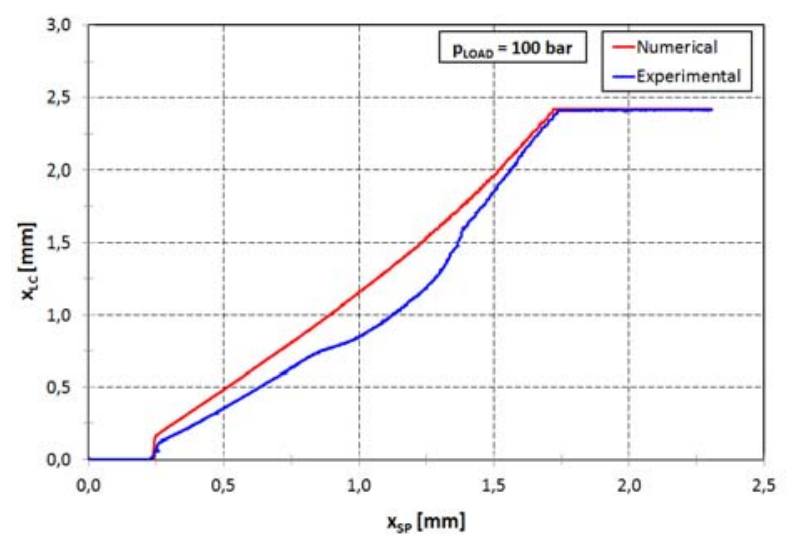

Fig. 12 Local compensator displacement numerical vs. experimental comparison $\left(p_{L O A D}=100\right.$ bar $)$.

this operating parameter, the numerical prediction is not properly reliable for the whole simulated range, being the differences mainly originated by the difficulties encountered in the estimation of the spool-sleeve contact and viscous frictions. Although this drawback, the local compensator maximum opening instant $\left(x_{L C} \cong 2.4 \mathrm{~mm}\right.$ ) is correctly calculated.

The same tendencies characterize also the results calculated for a higher pressure load of about 200 bar, depicted in Figs. 13-17. In this case, the numerical results accuracy is even improved, particularly for pressure (Figs. 13-15) and flow rate (Fig. 16) trends, with maximum percentage errors limited to less than $1.5 \%$. A better comparison has been also achieved for the local compensator displacement (Fig. 17), because the influence of contact and viscous frictions is less significant at higher pressure loads. 


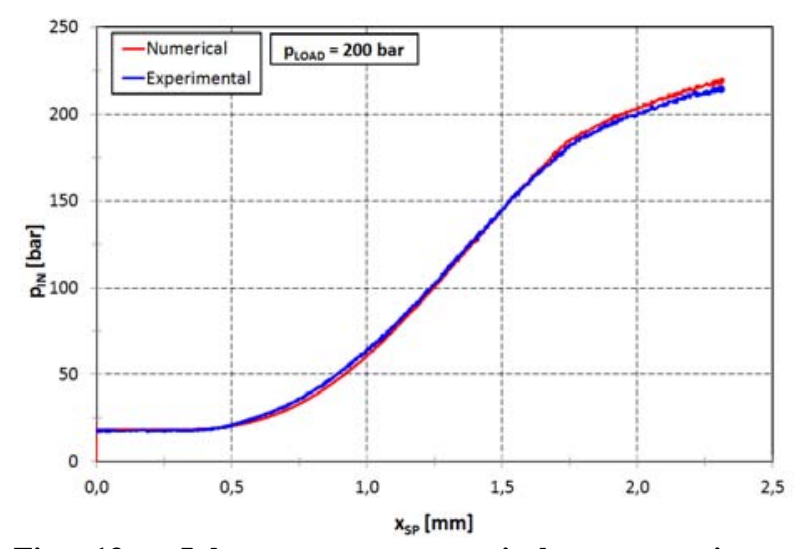

Fig. 13 Inlet pressure numerical vs. experimental comparison $\left(p_{L O A D}=200\right.$ bar $)$.

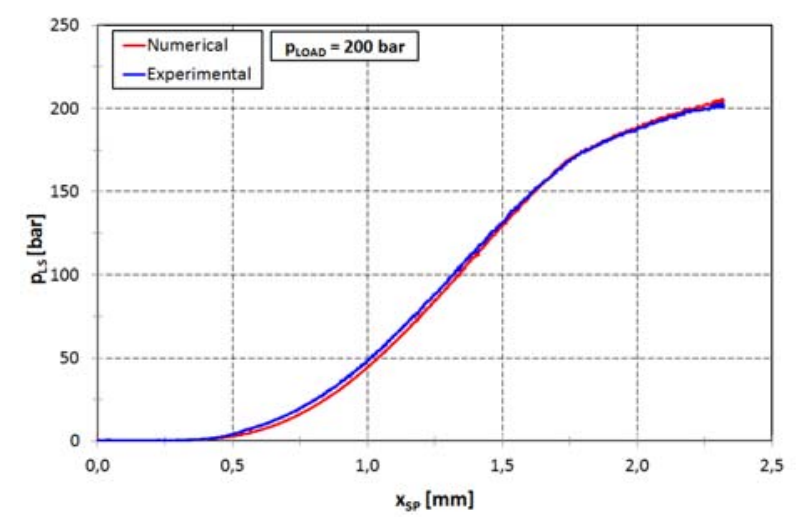

Fig. 14 Load sensing pressure numerical vs. experimental comparison $\left(p_{L O A D}=200\right.$ bar $)$.

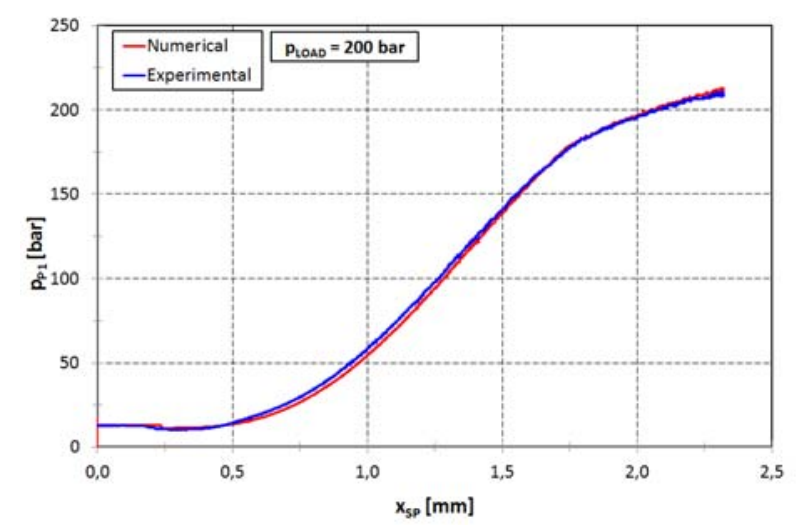

Fig. 15 Local compensator downstream pressure numerical vs. experimental comparison ( $p_{L O A D}=200$ bar).

\subsection{Control Valve Performance Improvement}

Once stated the consistency of the CAE methodology here presented, its predictive capability has been applied with the aim to increase the control valve performance, mainly in terms of hydraulic efficiency and maximum controlled flow rate. In order to accomplish these

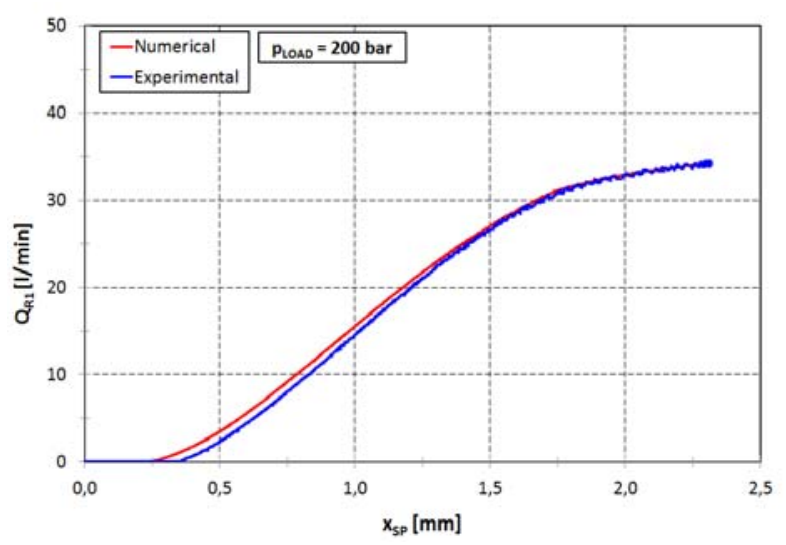

Fig. 16 First slice volumetric flow rate numerical vs. experimental comparison $\left(p_{L O A D}=200\right.$ bar $)$.

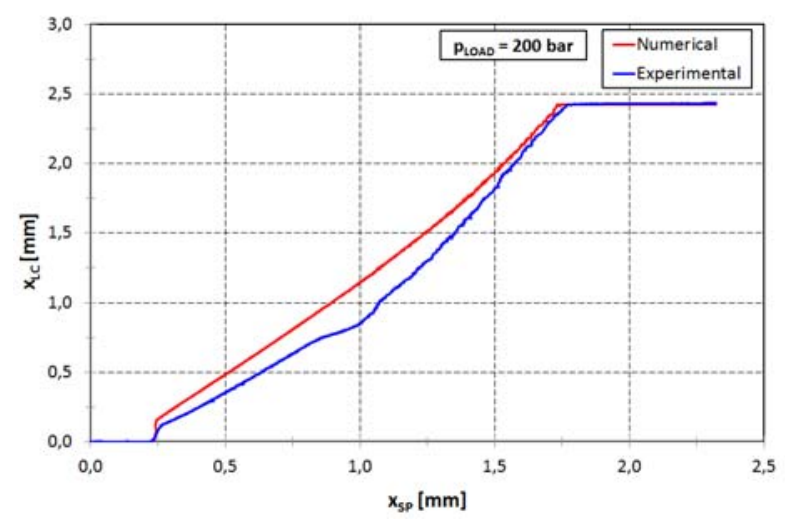

Fig. 17 Local compensator displacement numerical vs. experimental comparison $\left(p_{L O A D}=200\right.$ bar $)$.

challenging targets, two strategies have been followed, respectively based on an overall increase of the control valve internal ducts permeability and by varying the stiffness of the local compensator spring.

The first strategy has been carried out identifying three alternative design solutions for the control valve with a progressively reduced hydraulic resistance. More in details, these alternative configurations, respectively called Evo1, Evo2 and Evo3, have been obtained by gradually enlarge all the control valve internal ducts diameters of a fixed percentage with respect to the baseline geometry (Table 2).

As in the previous paragraph, in Figs. 18 and 19, the volumetric flow rate through the first slice, $Q_{R 1}$, and the local compensator displacement, $x_{L C}$, computed for a medium load pressure value $\left(p_{L O A D}=150\right.$ bar $)$, are presented as a function of the main spool displacement, $X_{S P}$. 
Table 2 Control valve internal ducts diameters percentage increase.

\begin{tabular}{llll}
\hline \multicolumn{4}{l}{ Simulated cases } \\
\hline Name & Evo1 & Evo2 & Evo3 \\
$\Delta d(\%)$ & 12.5 & 25 & 45 \\
\hline
\end{tabular}

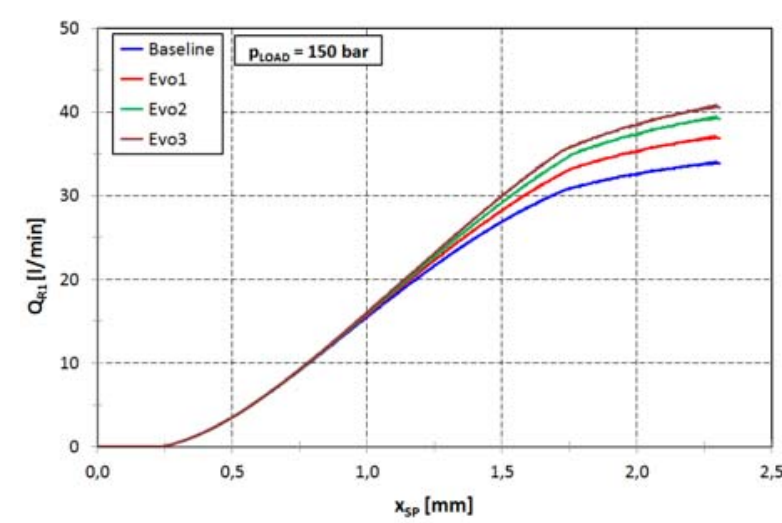

Fig. 18 Influence of the overall control valve hydraulic permeability on the metering curve $\left(p_{L O A D}=150 \mathrm{bar}\right)$.

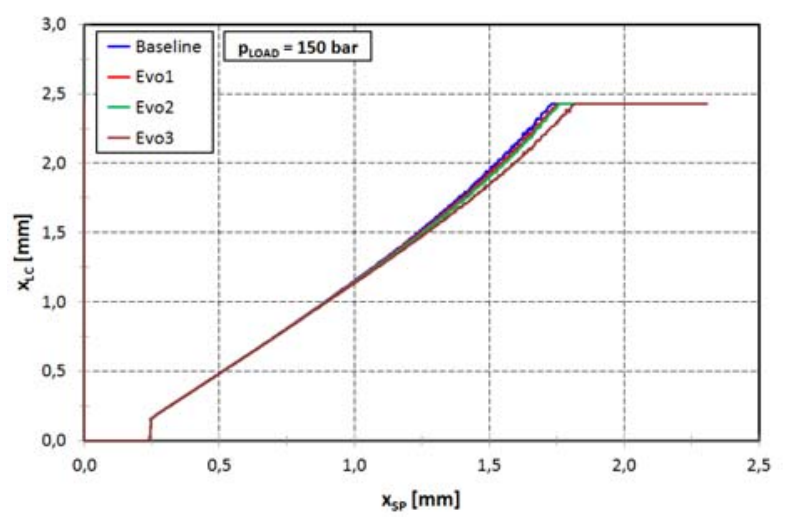

Fig. 19 Influence of the overall control valve hydraulic permeability on the local compensator displacement ( $p_{L O A D}$ = 150 bar).

In Fig. 18, the metering curves calculated for the three evolved configurations are compared with the baseline solution: for all the simulated cases, the maximum controlled flow rate is less than the higher value achieved when the main spool is fully opened $\left(x_{S P}=2.3 \mathrm{~mm}\right)$. In particular, the best performance can be noticed for the Evo3 configuration, which reaches a highest volumetric flow rate of about $41 \mathrm{~L} / \mathrm{min}$ with a maximum controlled value of about $35.5 \mathrm{~L} / \mathrm{min}$.

These considerations are also confirmed by the analysis of the local compensator displacement trends illustrated in Fig. 19. In this case, for all configurations, the local compensator maximum stroke is reached before the control valve is fully opened. Therefore, the maximum controlled volumetric flow rate can be improved if the local compensator opening is delayed.

Consequently, further simulations have been completed in order to assess the influence of the local compensator spring pre-load on the control valve metering curve. For this purpose, as summarized in Table 3, the best performing configuration (Evo3) has been chosen and two spring pre-load percentage reductions, respectively equal to $10 \%$ and $20 \%$, have been considered. In this case, the numerical curves, calculated for the volumetric flow rate, $Q_{R 1}$, and the local compensator displacement, $x_{L C}$, applying a pressure load of about 150 bar, are depicted in Figs. 20 and 21.

First of all, analyzing the metering curves shown in Fig. 20, higher values of the maximum controlled volumetric flow rate can be observed, for both the spring pre-loads considered. More in details, the best performance is achieved for the lower pre-load decrease (pre-load A in Table 3), where the maximum controlled flow rate is enhanced up to $40 \mathrm{~L} / \mathrm{min}$.

These considerations can be better understood examining also the local compensator displacement curves illustrated in Fig. 21. In fact, for the lower spring pre-load configuration (pre-load B in Table 3), the local compensator is not yet fully opened when the control valve main spool completes its stroke $\left(x_{L C} \cong 2.2\right.$ $\mathrm{mm}$ for $x_{S P}=2.3 \mathrm{~mm}$ ), determining an appreciable volumetric flow rate limitation $\left(Q_{R 1, \max } \cong 39.8 \mathrm{~L} / \mathrm{min}\right)$.

\section{Conclusions}

In this paper a CAE methodology, based on a combined use of multidimensional CFD simulations and lumped and distributed numerical modeling, has been proposed and applied for studying the metering characteristics of an electro-hydraulic load-sensing proportional control valve.

Firstly, the methodology has been validated through a detailed numerical versus experimental comparison, performed for a wide range of operating conditions, in 
Table 3 Local compensator spring pre-load percentage reduction.

\begin{tabular}{lll}
\hline & Evo3 simulated cases \\
\hline Name & Pre-load A & Pre-load B \\
$\Delta F_{0}(\%)$ & -10 & -20 \\
\hline
\end{tabular}

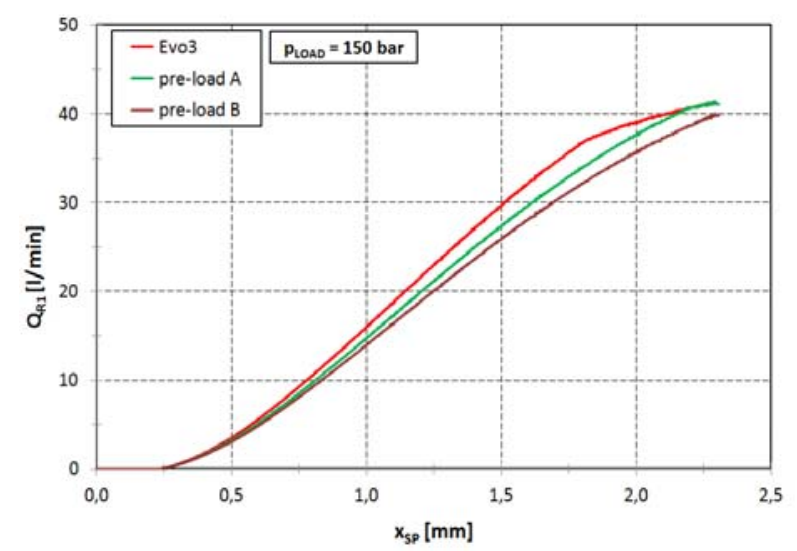

Fig. 20 Influence of the local compensator spring pre-load on the metering curve $\left(p_{L O A D}=150\right.$ bar $)$.

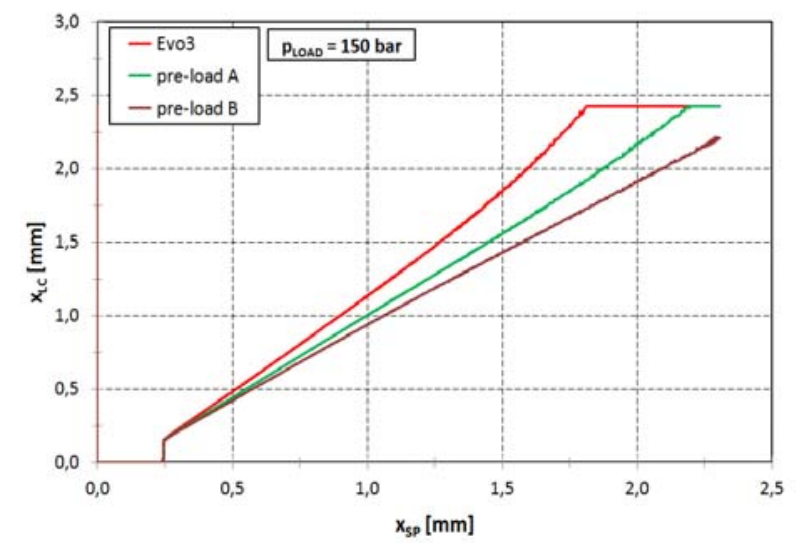

Fig. 21 Influence of the local compensator spring pre-load on its displacement $\left(p_{L O A D}=150\right.$ bar $)$.

terms of both pressure loads and metered flow rates. A general good accuracy has been obtained for the whole control valve operating field, being the maximum percentage differences always lower than $3 \%$.

Then, this computation approach has been employed in order to increase the control valve performance, mainly in terms of pressure drop reduction and maximum controlled flow rate. The influence of some design parameters, like the internal ducts geometrical features and the local compensator spring pre-load, has been evaluated and an optimized solution has been proposed and verified.
More in details, the simulation results demonstrate that a significant improvement for the valve controllability can not be achieved by only widening the internal channels dimensions, but a further reduction of the local compensator spring pre-load is needed. Finally, for the most reliable design configuration, the maximum controlled flow rate has been enhanced from $31 \mathrm{~L} / \mathrm{min}$ to $40 \mathrm{~L} / \mathrm{min}$.

\section{Acknowledgments}

The authors would like to acknowledge Brevini Fluid Power S.p.A. (Reggio Emilia, Italy) and, in particular, Mr. Bartoli, Dr. Montanari and Mr. Giliberti for their support to the experimental testing development.

\section{References}

[1] J.F. Blackburn, G. Reethof, J.L. Shearer, Fluid Power Control, M.I.T. Technology Press \& John Wiley \& Sons, New York, 1960.

[2] H.E. Merrit, Hydraulic Control Systems, John Wiley \& Sons, New York, 1967.

[3] T.J. Viersma, Analysis, Synthesis and Design of Hydraulic Servosystems and Pipelines, Elsevier Scientific Publishing Co., Amsterdam, 1980.

[4] D.N. Johnston, K.A. Edge, N.D. Vaughan, Experimental investigation of flow and force characteristics of hydraulic poppet and disk valves, Proceedings of the Institution of Mechanical Engineers, Part A, Journal of Power and Energy 205 (1991) 161-171.

[5] J. Lugowsky, Experimental investigation on the origin of flow forces in hydraulic piston valves, in: 10th International Conference on Fluid Power, BHRA, Brugges, Belgium, Apr. 5-7, 1993.

[6] G. Ferretti, R. Paoluzzi, G.L. Zarotti, CFD flow analysis of steady-state flow forces on valves, in: Proceedings of the 2nd ISFP, Shanghai, China, 1995.

[7] M. Borghi, G. Cantore, M. Milani, R. Paoluzzi, Analysis of hydraulic components using computational fluid dynamics models, Proceedings of the Institution of Mechanical Engineers, Part C, Journal of Mechanical Engineering Science 212 (7) (1998) 619-629.

[8] R. Amirante, G. Del Vescovo, A. Lippolis, Flow forces analysis of an open center hydraulic directional control valve sliding spool, Energy Conversion and Management 47 (2006) 114-131.

[9] R. Amirante, G. Del Vescovo, A. Lippolis, Evaluation of the flow forces on an open center directional control valve 
by means of a computational fluid dynamic analysis, Energy Conversion and Management 47 (2006) 1748-1760.

[10] M. Fabiani, S. Mancò, N. Nervegna, M. Rundo, G. Armenio, C. Pachetti, et al., Modelling and simulation of gerotor gearing in lubricating oil pumps, SAE Technical Paper 1999-01-0626, 1999.

[11] S. Mancò, N. Nervegna, M. Rundo, A contribution to the design of hydraulic lube pumps, The International Journal of Fluid Power 3 (1) (2002) 21-31.

[12] LMS Imagine.LAB AMESim, Rev. 9, Reference manual, 2009.

[13] C. Angeloni, F. Franzoni, L. Montorsi, M. Milani, F. Paltrinieri, A transient multidimensional CFD approach of a control valve using non-Newtonian fluids, in: Proceedings of the Twelfth Scandinavian International Conference on Fluid Power, Tampere, Finland, May 18-20, 2011. 